\title{
PERBEDAAN MEDIA EDUKASI (BOOKLET DAN VIDEO) TERHADAP KETRAMPILAN KADER DALAM DETEKSI DINI STUNTING
}

\author{
Qona Lutfi sartika,Katrin Dwi Purnanti \\ Poltekkes Kemenkes Semarang \\ Email: qonalutfi09@gmail.com
}

\begin{abstract}
In $201722.2 \%$ or 150.8 million children under five in the world were stunted. 55\% came from Asia. 9 million are in Indonesia. Stunting has many implications, a very important impact, according to the UNICEF study in Cebu by the University of North Carolina, which found that the IQ scores of stunted children of age were lower. According to WHO, efforts that can be implemented are Community Empowerment. In an effort to improve cadre skills, educational media are needed that support the learning process. This study aims to determine the effect of differences in educational media (booklets and videos) on skills in early detection of stunting in toddlers. This type of research is a pre-experiment with a pretest-posttest control group design, the total sample is 15 control groups, 15 booklet groups and 15 video groups with sampling using consecutive sampling techniques. The data were processed using the Wilcoxon test, Paired t-test and Mann Whitney. The results showed that health education using audiovisual media and booklets was effective in improving the skills of cadres in screening. The effectiveness of providing booklet education media was carried out by thetest, in which Wilcoxon obtained a probability value $(p)<0.001$, which means that the video education media was effective in improving cadre skills in early detection of stunting. Conclusion: This study shows that video media is more effective in improving cadres' skills in early detection of stunting.
\end{abstract}

Keywords: Stunting; Booklet; Video

\section{ABSTRAK}

Pada tahun $201722,2 \%$ atau 150,8 juta balita di dunia mengalami stunting. 55\% berasal dari Asia. 9 Juta berada di indonesia. Stunting berdampak pada banyak hal, dampak yang sangat penting menurut UNICEF dari hasil studi di Cebu oleh University of North Carolina, menemukan bahwa skor IQ anak-anak stunting usia lebih rendah. Menurut WHO upaya yang dapat dilaksanakan dengan Pemberdayaan Masyarakat. Dalam upaya peningkatan keterampilan kader diperlukan media edukasi yang mendukung proses pembelajaran. Penelitian ini bertujuan untuk mengetahui pengaruh perbedaan media edukasi (booklet dan video) terhadap keterampilan dalam deteksi dini stunting pada balita. Jenis penelitian ini adalah pre eksperimen dengan pretest-posttest control group design, jumlah sampel 15 kelompok Kontrol, 15 kelompok Booklet dan 15 Kelompok Video dengan pengambilan sampel menggunakan teknik consecutive sampling. Data diolah menggunakan uji wilcoxon, Paired t-test dan Mann Whitney. Hasil penelitian menunjukkan pendidikan kesehatan menggunakan media audiovisual dan booklet efektif dalam meningkatkan keterampilan kader dalam melakukan skrining. efektifitas pemberian media edukasi booklet maka dilakukan uji Wilcoxon didapatkan nilai probabilitas $(p)<0,001$ yang berarti media edukasi video efektif dalam meningkatkan keterampilan kader dalam deteksi dini stunting. Penelitian menunjukan media video lebih efektif dalam meningkatkan keterampilan kader dalam deteksi dini stunting.

Kata Kunci: Stunting; Booklet; Video 


\section{Pendahuluan}

Stunting (kerdil) adalah kondisi dimana balita memiliki panjang atau tinggi badan yang kurang jika dibandingkan dengan umur. Kondisi ini diukur dengan panjang atau tinggi badan yang lebih dari minus dua standar deviasi median standar pertumbuhan anak dari WHO. (Pusat Data dan Informasi Kemenkes RI, 2018)

Kejadian balita pendek atau biasa disebut dengan stunting merupakan salah satu masalah gizi yang dialami oleh balita di dunia saat ini. Pada tahun 2017 22,2\% atau sekitar 150,8 juta balita di dunia mengalami stunting. Namun angka ini sudah mengalami penurunan jika dibandingkan dengan angka stunting pada tahun 2000 yaitu 32,6\%. Pada tahun 2017, lebih dari setengah balita stunting di dunia, 2018 berasal dari Asia (55\%) sedangkan lebih dari sepertiganya (39\%) tinggal di Afrika. Dari 83,6 juta balita stunting di Asia, proporsi terbanyak berasal dari Asia Selatan $(58,7 \%)$ dan proporsi paling sedikit di Asia Tengah (0,9\%) Pusat Data dan Informasi Kemenkes RI, 2018).

Data prevalensi balita stunting yang dikumpulkan World Health Organization (WHO), Indonesia termasuk ke dalam negara ketiga dengan prevalensi tertinggi di regional Asia Tenggara/South-East Asia Regional (SEAR). Rata-rata prevalensi balita stunting di Indonesia tahun 2005-2017 adalah $36,4 \%$. Pusat Data dan Informasi Kemenkes RI, 2018)

Stunting berdampak pada banyak hal anatara lain obesitas, anak stunting memiliki rasio 2,7 kali menjadi obesitas dari anak yang tidak stunting (isabel Bove, 2012). Selain itu menyebabkan serangkaian perubahan penting pengeluaran energi yang lebih rendah, lebihnrentan terhadap efek dari diet tinggi lemak, rendah lemak oksidasi serta gangguan metabolisme lemak sehingga potensi kenaikan berat badan tidak terbatas (Ghaida Yasmin at al, 2014). Dampak y yang sangat penting menurut UNICEF dari hasil studi di Cebu oleh University of North Carolina, menemukan bahwa skor IQ anak-anak stunting usia delapan tahun lebih rendah 11 point dibandingkan dengan anak-anak yang tidak stuntibg. (UNICEF, 1998).

World Health Assembly (WHA) menargetkan tahun 2015 penurunan prevalensi balita stunting sebesar $40 \%$ dari prevalensi saat ini, untuk mencapai target tersebut semua unsur dilibatkan baik dari pusat, provinsi, kabupaten/ kota sampai tingkat masyarakat. Upaya yang harus dilakukan ditingkat masyarakat dalam menurunkan prevalensi stunting, yaitu melalui meningkatkan partisipasi masyarakat, agar merasa memiliki dan berkonstribusi dalam program penanggulangan stunting, atau dapat pula melalui pemberdayaan kelompok-kelompok yang ada (WHO, 2013). Kegiatan yang telah dilaksanakan di Indonesia berupa pemantauan status gizi, dan dapat diartikan sebagai penilaian status gizi, karena kegiatan ini dilaksanakan hanya setahun sekali, pada kabupaten kota yang terpilih, tujuannya untuk memperoleh informasi prevalensi balita stunting (Kemenkes RI, 2014)

Kartu menuju sehat (KMS) digunakan untuk memantau pertumbuhan berdasarkan standar buku WHO antro 2005 dengan menggunakan indeks Berat Badan menurut Umur (BB/U). Indeks ini tidak dapat memantau kejadian stunting pada balita. Sehingga perlu adanya KMS berdasarkan indeks tinggi badan atau panjang badan menurut umur (TB-PB/U) yang dapat digunakan untuk mendeteksi kejadian stunting pada anak balita. (Kemenkes, 2010) sebagai suatu masalah, agar mereka memiliki motivasi untuk melakukan pencegahanyya pada tingkat rumah tangga dan memanfaatkan layanan yang tersedia untuk meningkatkan pertumbuhan dan perkembangan anak (WHO, 2013). Melalui kader yang dipilih oleh masyarakat, dapat membantu mengidentifikasi masalah, mengembangkan kapasitas agar masyarakat dapat menangani masalah yang dihadapi secara lebih efektif, untuk itu kader perlu memiliki pengetahuan dan ketrampilan dalam melaksanakan kegiatanya. Dalam upaya peningkatan ketrampilan kader diperlukan media edukasi yang mendukung proses pembelajaran ini. Media video merupakan media pendidikan elektronik dalam bentuk audiovisual yang mengikutsertakan beberapa panca indera 
sehingga sangat menarik dan mudah dipahami. Sedangkan booklet menurut teori Satmoko (Septiwiharti, 2015:28) Booklet adalah sebuah buku kecil berukuran 14,8 x $21 \mathrm{~cm}$ yang memiliki paling sedikit lima halaman tetapi tidak lebih dari 48 halaman diluar hitungan sampul. Sedangkan menurut teori Holmes (Mintarti, 2001:24) booklet memuat lembaran-lembaran paling banyak 20 halaman dengan ukuran $20 \times 30 \mathrm{~cm}$ yang dijilid dalam satu satuan, dengan berbagai visual yakni: huruf, foto, gambar garis atau lukisan. Isi suatu booklet bersifat jelas, tegas, mudah dimengerti dan menarik. Berdasarkan permasalahan di atas makapenelitan ini dimaksukan untuk meliahat perbedaan media edukasi (modul dan video) terhadap ketrampilan dalam deteksi dini stunting pada balita.

\section{Metode Penelitian}

Penelitian ini termasuk quasi experiment dengan pretest-posttest control group design, yaitu desain penelitian yang terdapat pretest sebelum diberi perlakuan dan posttest setelah diberi perlakuan dengan menggunakan kelompok control. Sampel dalam penelitian ini adalah Kader Posyandu di wilayah Kerja Puskesmas Baturraden 2 sejumlah 45 dengan rincian 15 kader pada kelompok booklet, 15 kader pada kelompok video dan 15 kader dalam kelompok control. Pada Minggu 1 tiap kemolpok kader di ambil nilai ketrampilan dalam mendektesi stunting kemudian pada kelompok pertama yaitu kader yang diberikan media edukasi berupa booklet tentang deteksi dini stunting dan kelompok kedua kader diberikan media edukasi dalam bentuk video dan kelompok ketiga adalah kelompok kontrol yaitu tidak diberikan intervensi apapun. Setelah 3 hari kader dinilai kembali dalam ketrampilan deteksi dini stunting.

\section{Hasil dan Pembahasan}

Deskripsi karakteristik dariresponden dikelompokan berdasarkan Umur, Pendidikan dan ketrempilan kader. Pada umur di kemompokan menjadi 2 yaitu kurang dari 35 tahun dan lebih dari 35 tahun sedangkan pada katefori Pendidikan dikategorikan sesuai kategori Pendidikan, masing-masing kelompok disajikan dalam tabel berikut :

Tabel 1.1 Distribusi frekuensi Umur dan Pendidikan

\begin{tabular}{llll}
\hline Kelompok & Parameter & $\mathrm{N}$ & $\%$ \\
\hline \multirow{4}{*}{ Booklet } & Umur & & \\
& $\geq 35$ th & 15 & 73 \\
Video & $<35$ th & & 27 \\
& $\geq 35$ th & 15 & 67 \\
Kontrol & $<35$ th & & 33 \\
& $\geq 35$ th & 15 & 60 \\
& $<35$ th & & 40 \\
Booklet & Pendidikan & & \\
& SD & 15 & 33.3 \\
& SMP & & 33,3 \\
Video & SMA & & 33,3 \\
& SD & 15 & 40 \\
& SMP & & 33 \\
Kontrol & SMA & & 26 \\
& SD & 15 & 47 \\
& SMP & & 20 \\
& SMA & & 33 \\
\hline
\end{tabular}

Keterangan : $\mathrm{N}=$ jumlah sampel

Tabel 1.1. Data di atas dapat diketahui bahwa umur pada masing-masing Kelompok paling tinggi Kelompok Usia lebih dari atau sama dengan 35 Tahun dan dapat diketahui bahwa tingkat pendidikan kader pada kelompok booklet cendrung sama.

Tabel 1.2 Perbedaan Keterampilan Kader tentang Stunting Sebelum dan Sesudah diberikan perlakuan

\begin{tabular}{cccc}
\hline Kelompok & Mean $\pm S D$ & Max & Min \\
& & & \\
\hline Booklet & $14,26 \pm 3,12$ & 9 & 20 \\
Video & $14,66 \pm 3,19$ & 11 & 20 \\
Kontrol & $14,86 \pm 2,92$ & 11 & 20 \\
& & & \\
\hline
\end{tabular}

Tabel 1.2 menunjukkan nilai rata-rata, maksimum, minimum dan standar deviasi keterampilan kader pada masing-masing kelompok perlakuan dan kelompok kontrol setelah diberikan perlakuan. Data di atas dapat diketahui bahwa nilai mean ketrampilam pada masing-masing kelompok perlakuan cenderung seragam.

Uji normalitas telah dilakukan menggunakan uji statistik Saphiro Wilk, 
semua sebaran data normal dengan nilai $p>0,05$. Kecuali kelompok pre tes dengan perlakuan video.

Tabel 1.3 Perbedaan Keterampilan Kader tentang Stunting Sebelum dan Sesudah diberikan Booklet

\begin{tabular}{lrrrl}
\hline Ketrampilan & Mean & Med $\begin{array}{l}\text { Min } \\
-\end{array}$ & $\begin{array}{l}\text { Paired } \\
\text { T-Test }\end{array}$ \\
\hline Sebelum & 14,3 & 14 & $9-20$ & p value \\
Sesudah & 22,7 & 23 & $19-26$ & $=0,000$ \\
\hline
\end{tabular}

Berdasarkan tabel 1.3 menunjukkan bahwa hasil uji statistik Paired T-Test didapatkan $p$-value 0,000 artinya ada perbedaan yang bermakna keterampilan kader tentang stunting sebelum dan sesudah diberikan booklet.

Tabel 1.4 Perbedaan Keterampilan Kader tentang Stunting Sebelum dan Sesudah diberikan Video

\begin{tabular}{llrll}
\hline Ketrampilan & Mean & Med & $\begin{array}{l}\text { Min }- \\
\text { Max }\end{array}$ & Wilcoxon \\
\hline Sebelum & 15 & 13 & $11-20$ & p value \\
Sesudah & 23 & 23 & $19-25$ & $=0,000$ \\
\hline
\end{tabular}

Tabel 1.4 menunjukkan bahwa hasil uji statistik Wilcoxon didapatkan p-value 0 , artinya ada perbedaan yang bermakna keterampilan kader tentang stunting sebelum dan sesudah diberikan video

Tabel 1.5 Perbedaan Keterampilan Kader tentang Stunting pada Kelompok Kontrol

\begin{tabular}{llrll}
\hline Ketrampilan & Mean & Med & $\begin{array}{l}\text { Min }- \\
\text { Max }\end{array}$ & $\begin{array}{l}\text { Paired } \\
\text { T-Test }\end{array}$ \\
\hline Sebelum & 15 & 15 & $11-20$ & p value \\
Sesudah & 15 & 16 & $11-20$ & $=0,1,64$ \\
\hline
\end{tabular}

Berdasarkan tabel 1.5 menunjukkan bahwa hasil uji statistik Paired T-Test didapatkan $p$-value 0,000 maka artinya tidak ada perbedaan yang bermakna keterampilan kader tentang stunting pada kelompok kontrol.

Tabel 1.6 menunjukkan bahwa Berdasarkan hasil Mann-Whitney di peroleh $p$ value bahwa kelompok booklet dan video tidak memiliki perbedaan dengan $p$ value 0,902 . Sedangkan kelompok booklet dengan kontrol memiliki $p$ value sebesar
$0,000(<0,05)$ yang memiliki makna terdapat perbedaan yang signifikan antara dua kelompok dan kelompok video dan kontrol memiliki perbedaan yang signifikan dengan $p$ value $0,000(0,05)$.

Tabel 1.6 Perbandingan Keterampilan Kader antara Kelompok Perlakuan dengan Kelompok Kontrol

\begin{tabular}{lc}
\hline \multicolumn{1}{c}{ Pasangan Perlakuan } & $p$-value \\
\hline Booklet vs Video & 0.902 \\
Booklet vs Kontrol & 0.000 \\
Video vs Kontrol & 0.000 \\
\hline
\end{tabular}

Pada penelitian ini di dapatkan hasil bahwa terdapat peningkatan ketrampilan pada kelompok pemberian media edukasi booklet sebelum dan sesudah diberikan perlakuan. Untuk menunjukan efektifitas pemberian media edukasi booklet maka dilakuakan uji paried t-tes didapatkan nilai probabilitas $(p)<0,000$ (table 1.3), yang berarti media edukasi booklet efektif dalam meningkatkan keterampilan kader dalam deteksi dini stunting.

Keterampilan yang semakin baik disebabkan responden telah mendapatkan pengetahuan yang baik. Jika responden memiliki pengetahuan yang baik dalam tingkatan aplikasi maka akan membuat responden memiliki kemampuan untuk menggunakan materi yang telah dipelajari pada media edukasi booklet. Segala informasi yang didapatkan dari penyuluhan dan penyertaan materi dalam booklet akan membuat responden akan semakin baik lagi dalam melakukan deteksi dini pada stunting. Pemberian informasi dalam bentuk booklet ternyata mampu meningkatkan pengetahuan kader yang berdampak positif terhadap keterampilan yang terbentuk. Perubahan Keterampilan dipengaruhi oleh faktor pengetahuan yang didapatkan darihasil penginderaan, salah satunya didapatkan pada pendidikan dan proses belajar.

Hal ini sesuai penelitian yang silakukan oleh Siti (2020) bahawa pemanfaatan booklet berpengaruh pada kelas ibu dan anak terhadap peningkatan ketrampilan ibu dalam kegawatdaruratan kejang demam pada balita. Berdasarkan hasil penelitian Mahmudah (2018) yang 
berjudul pengaruh penyuluhan kesehatan dengan booklet terhadap praktik ibu dalam memberikan pengetahuan personal hygiene pada saat menstruasi pada anak berkebutuhan khusus menyimpulkan bahwa pendidikan kesehatan dengan booklet mempunyai dampak dan pengaruh pada sikap dan praktik seseorang menjadi lebih baik dan menjadi tahu. Terbentuknya suatu perilaku baru, terutama pada orang dewasa dimulai pada domain kognitif, dalam arti subjek tahu terlebih dahulu terhadap stimulus yang berupa materi atau objek di luarnya, sehingga menimbulkan pengetahuan baru pada subjek tersebut. Ini selanjutnya menimbulkan respon batin dalam bentuk sikap si subjek terhadap objek yang diketahui itu. Akhirnya rangsangan yakni objek yang telah diketahui dan disadari sepenuhnya tersebut akan menimbulkan respon lebih jauh lagi, yaitu berupa tindakan (action) terhadap atau sehubungan dengan stimulus atau objek tadi.

Media booklet mempunyai kelebihan dapat menyesuaikan kader belajar mandiri, kader dapat melihat isinya lebih santai, informasi dapat dibagi baik dengan keluarga dan tetangga, dapat memberikan detail menggunakan gambar untukpenguatan pesan. Disamping memiliki keunggulan, kelemahan booklet dan mudah hilang sehingga peneliti memberikan batasan waktu 3 hari untuk penyerapan informasi agar media masih ada dan utuh.booklet sebagai media yang digunakan dalam media edukasi diharapkan mampumemberikan informasi kesehatan yang sesuai dengan tingkat penerimaan kader sehingga kader mau dan mampu mengubah perilaku sesua idengan informasi yang terdapat dalam booklet.

Pada penelitian ini di dapatkan hasil bahwa terdapat peningkatan ketrampilan pada kelompok pemberian media edukasi video sebelum dan sesudah diberikan perlakuan. Untuk menunjukan efektifitas pemberian media edukasi booklet maka dilakuakan uji wilcoxson didapatkan nilai probabilitas $(p)<0,001$ (tabel 1.4), yang berarti media edukasi video efektif dalam meningkatkan keterampilan kader dalam deteksi dini stunting.
Dalam penelitian ini kader mengalami peningkatan keterampilan setelah diberikan media edukasi video deteksi dini stunting. Media video deteksi dini stunting menyajikan informasi tentang pengertian stunting, tanda gejala stunting, dapampak stunting cara mengukur panjang badan bayi dan cara menentukan stunting. Media edukasi video menyampaikan pesan dalam bentuk cerita dengan suara yang lugas yang disertai gambar yang mencontohkan perilaku yang seharusnya dilakukan dan seharusnya tidak boleh dilakukan. Media film atau video membantu responden yang memiliki usia 41-50 tahun yang memiliki kesulitan dalam membaca dan responden yang memiliki pendidikan SMP sehingga pemberian penyuluhan dengan media film memberikan keunggulan dibandingkan media lainnya.

Hal ini sesuai dengan penelitian Ammelda (2013) yang memperlihatkan bahwa modeling media video meningkatkan keterampilan toilet training pada anak toddler. Hal ini diperkuat oleh hasil dari penelitan ini sejalan dengan Efektifitas penelitian yang dilakukan oleh Sri Widatiningsih, Tuti Sukini dan Siti Rofi'ah (2017) yang berjudul effectiveness of movie to improve knowledge, attitude and behaviour in preventing HIV transmission from mother to child. Hasil penelitian menunjukkan bahwa media video berpengaruh signifikan terhadap peningkatan pengetahuan dan sikap tentang PMCTC HIV. Tingkat kepercayaan yang digunakan yaitu $95 \%$.

Pada penelitian ini dilakukan uji multifariat antar kelompok pelakuan kelompok booklet, kelompok video dan kelompok control menggunakan uji Uji lanjut Kruskal Wallis. Hasil Mann-Whitney (tabel 1.6) di peroleh $p$ value bahwa kelompok booklet dan video tidak memiliki perbedaan dengan $p$ value 0,000 Sedangkan kelompok booklet dengan kontrol memiliki $p$ value sebesar $0,902(<0,05)$ yang memiliki makna terdapat perbedaan yang signifikan antara dua kelompok dan kelompok video dan kontrol memiliki perbedaan yang signifikan dengan $p$ value $0,000 \quad(0,05)$.Pemberian media edukasi booklet dan video memiliki efektifitas yang sama dalam peningkatan ketrampilan kader dalam deteksi dini stunting. 
Media edukasi booklet memiliki kelebihan memberikan informasi yang rinci dan menarik serta dapat di ulang kapan saja. Menurut Penelitian Arif Putra (2013) Media Video lebih efektif terhadap perubahan pengetahuan dan sikap tenhadap perubahan sikap pada terhadap bahaya Napza. Hal ini mencerminkan penyerapan informasi lebih efektif dengan menggunakan indra pengelihatan dan pendengaran yang berupa video dibandingkan hanya menggunakan indra penglihatan saja yaitu berupa leaflet. Media edukasi booklet memiliki kelebihan memberikan informasi yang rinci dan menarik serta dapat di ulang kapan saja. Media film atau video merupakan media yang dapat menyajikan pesan yang dapat bersifat informatif, edukatif maupun instruksional. Media edukasi video sangat baik untuk menyajikan teori dan praktik, menghemat waktu untuk melakukan penjelasan.

\section{Kesimpulan}

Media Edukasi booklet dan video efektif dalam meningkatkan ketrampilan kader dalam deteksi dini Stunting pada bayi. Media edukasi dengan video lebih direkomendasikan dalam memberikan edukasi karena penyerapan informasi lebih efektif dengan menggunakan indra pengelihatan dan pendengaran yang berupa video dibandingkan hanya menggunakan indra penglihatan saja.

\section{Ucapan Terima Kasih}

Ucapan terima kasih kami sampaikan kepada Kepala Dinas Kesehatan Kabupaten Banyumas, Kepala Puskesmas Baturraden II Dan jajarannya yang telah memberikan ijin dan membantu proses pelaksanaan penelitian serta Poltekkes Kemenkes Semarang yang telah memberikan pembiayaan penelitian.

\section{Daftar Pustaka}

Aumeistere, Ciprovica, Zavadska, Borisova. Zinc Content in Breast Milk and Its Association with Maternal Diet. 2018 [Diakses 8 Oktober 2019]. Didapat dari https://www.ncbi.nlm.
nih.gov/pmc/articles/PMC6213150/

Dewi, Ratna. 2019. Hubungan Kadar Zink Dalam Asi Dengan Berat Badan Dan Panjang Badan Bayi Usia 4-6 Bulan Di Kota Padang Sumatera Barat. Padang : Jurnal Akademikan Baiturrahman. 2019

Dorea J.G. Is zinc a first limiting nutrient in human milk? Nutr. Res. 1993;13:659-666. doi: 10.1016/S0271-5317(05)80558-5. [ CrossRef] [Google Scholar]

European Food Safety Authority (EFSA), Parma, Italy. SCIENTIFIC OPINION Scientific Opinion on Dietary Reference Values for zinc1 EFSA Panel on Dietetic Products, Nutrition and Allergies (NDA). 2014. (Diakses 9 Oktober 2019). Didapat dari

https://efsa.onlinelibrary.wiley.com/ doi/epdf/10.2903/j.efsa.2014.3844

Hamdiyah. Perbedaan Konsentrasi Zinc Pada Air Susu Ibu Antara Status Gizi Baik Dan Kurang Energi Kronik Postpartum. Makasar : Fakultas Kedokteran Universitas Hasanudin ; 2018

Javad M.T., Vahidinia A., Samiee F., Elaridi J., Leili M., Faradmal J., Rahmani A. Analysis of aluminum, minerals and trace elements in the milk samples from lactating mothers in Hamadan, Iran. J. Trace Elem. Med. Biol. 2018;50:8-15. doi: 10.1016/j.jtemb.2018.05.016. [Pub Med] [CrossRef] [Google Scholar]

Notoatmodjo, S. 2010. Metodologi Penelitian Kesehatan. Jakarta : Rineka Cipta.

Notoatmojo S. Kesehatan Masyarakat IImu dan Seni. Jakarta: Rineka Cipta; 2011.

Nasution, Ernawati. Efek suplementasi Zn dan Fe pada status gizi anak stunted usia 6-24 bulan di Kabupaten Kebumen Jawa Tengah. Yogyakarta : Universitas Gajah Mada; 2000

Qian J., Chen T., Lu W., Wu S., Zhu J. Breast milk macro- and micronutrient composition in lactating mothers from suburban and urban Shanghai. J. Paediatr. Child 
Health. 2010;46:115-120. doi: 10.1111/j.1440-1754.2009.01648.x. [ PubMed] [CrossRef] [Google Scholar]

Pusat Data dan Informasi Kementerian RI. 2018. Situasi Balita Pendek (Stunting)

Septiwiharti, L. (2015). Pengembangan Bahan Ajar Berbentuk Booklet Sejarah Indonesia pada Materi Pertempuran Lima Hari di Semarang terhadap Minat Belajar Siswa Kelas XI IPS SMA Negeri 1 Semarang Tahun Ajaran 2014/2015 (Doctoral dissertation, UNIVERSITAS NEGERI SEMARANG).

Sofyana Haris. Pemberian Dampak Pemberian Nutrisi ASI dan Non Eksklusif Terhadap Perubahan Ukuran Antopometri Dan Status Imunitas Pada Neonatus Di RSUD AI Ihsan Provinsi Jawa Barat. Depok: Fakultas Kedokteran Universitas Indonesia; 2011

Sopiyudin, Muhammah. 2009. Besar Sampel dan cara Pengambilan Sampel dalam Penelitian Kedokteran dan Kesehatan. Jakarta : Salemba Medika

Sugiyono. 2010. Metode Penelitian Pendidikan Pendekatan Kuantitatif, kualitatif, dan R\&D. Bandung: Alfabeta
Winiarska-Mieczan A. Cadmium, lead, copper and zinc in breast

Winiarska-Mieczan A. Cadmium, lead, copper and zinc in breast milk in Poland. Biol. Trace Elem. Res. 2014;157:36-44. doi: 10.1007/s12011-013-9870-x. [PMC free article] [PubMed] [CrossRef] [Google Scholar]

WHO, UNICEF 2012. Early Childhood Development and Disability: A discussion paper. diakses pada 20 maret 2019. Didapat dari https://apps.who.int/iris/bitstream/ha ndle/10665/75355/9789241504065 eng.pdf;jsessionid=2DB53EFC7B72 C302D638E49B936EBDF4?sequen $\mathrm{ce}=1$ tanggal 18 februari 2019

World Health Organization (WHO) United Nations International Children's Fund (UNICEF) . Tracking Progress for Breastfeeding Policies and Programme. 2017 [Diakses 8 Oktober 2019]. Didapat dari http://www.who.int/nutrition/publicatio ns/infantfeeding/global-bf-scorecard2017.pdf

Yasmin, G., Kustiyah, L., \& Dwiriani, C. M. (2014). Risk factors of stunting among school-aged children from eight provinces in Indonesia. Pakistan Journal of Nutrition, 13(10), 557. 